which is also apparent in other places, but some such title as "Visible Radiation" might, therefore, have been more appropriate. In the review in Nature of the first edition, it was suggested that the survey of coloured substances could advantageously have been combined with the chapter on the chemistry of colour, but it is now even more completely divorced, as an appendix. Chemical indicators are barely mentioned, despite their great interest.

Human vision, and subjective aspects of light and colour, are accorded an even more expanded treatment. As many workers in other branches of science, and in commerce and industry, never aspire to more precise colorimetric tools than colour charts, further considerations of the limitations and virtues of the popular colour dictionaries would have been welcome.

The third section is highly technical, discussing light sources from sun to candle, from arcs to fluorescent lamps, and the complicated apparatus and methods of modern light and colour measurement. A penultimate chapter concerned with the psychology of colour follows as comparatively light relief.

A very few pages headed "Colour in Nature" are unworthy of the rest of the book; they provide not a single clue to the relevant botanical, and only three references to the zoological, literature. It is a pity that one or more biologists were not included in the team of authors.

The second edition of "Colour" includes most of the original matter, much rearranged, and a good deal of new text, with additional figures. (Although the first edition only claimed three colour plates to the eight of the present book, in fact both have the same number of coloured illustrations, and only two of these have been substituted.) Changes in terminology are to be noted, and the new Appendix 3 is a valuable extract of definitions, for the most part internationally accepted, from the Physical Society's 1948 Report on Colour Terminology. Separate bibliographies for each chapter now replace scattered references in the text--a great improvement. A dual pagination with index references on a chapter rather than book basis seems a needless irritation. The amplified and revised text is, of course, more up to date and satisfactory to the specialist, and more valuable to him as a work of reference; almost inevitably it has also become less easy to read for the non-physicist seeking a comprehensive guide to the whole field of colour.

The first edition was criticized as expensive at 25s. After making allowance for the augmented text (but smaller format and more ordinary binding), even by to-day's standards the new edition seems no cheaper.

S. Clay

\section{AGRICULTURAL PHYTOPATHOLOGY}

\section{Disease in Plants}

An Introduction to Agricultural Phytopathology. By the late Dr. Neil E. Stevens and Prof. Russell B. Stevens. (Manual of the Plant Sciences, Vol. I.) Pp. $\mathrm{xx}+219$. (Waltham, Mass. : Chronica Botanica Co. ; London: Wm. Dawson, Sons and Co., Ltd., 1952.) 4.75 dollars.

7 HIS manual, written by two distinguished American pathologists, father and son, is based on a series of lectures, planned as self-contained chapters, on the general principles of plant pathology.
It does not treat of specific diseases and pathogens, but the entire subject-matter forms a comprehensive and valuable introduction to plant pathology designed, as the authors state, for the general reader as well as for the student and professional pathologist.

Stress is laid at the outset on the seriousness of the world food problem to-day, on measures of increased production and of possible preventable losses through disease control. These topics are discussed as part of the whole food situation in relation not only to food crops but also to the healthy production of timber stands and fibre plants as well.

Presumably for the benefit of the general reader, an early chapter (there are twenty in all) is devoted mainly to the anatomical structure and physiology of the healthy green plant, root, stem and leaf, this being followed by descriptions of pathological effects in these organs. The diagrams illustrating the normal anatomy are good and clear, but the same cannot be said of the few photomicrographs showing features of morbid anatomy.

Having already mentioned that bacteria and fungi are the principal instigators of disease, the authors, instead of first giving detailed consideration to these organisms, which are so easily demonstrable in affected tissues, proceed as early as in their third chapter to a consideration of viruses as agents of plant disease. Then follows a comparatively short account of bacteria and fungi, meagrely illustrated, this section closing with a table of classification of phytopathogenic forms. The occurrence, chemical nature, multiplication, mutation, transmission, symptoms, etc., of viruses and their effects are given brief but excellent treatment, this chapter being well illustrated in respect of symptoms of virus diseases. A section is also devoted to parasitic and hemiparasitic seed-bearing plants, and to injurious nematodes and insects. Excellent consideration again is given to nutritional and meteorological factors and to chemical injury in relation to the incidence of disease, with a full citation of relevant literature appended.

It is refreshing to find an entire section being devoted to the significance of such factors as the abundance and uniformity of the host plant when grown in close formation or pure stands, in contrast to growth in mixed culture as conducive to epidemic attacks; growing conditions-temperature, light and nutrition; and disease escape-resistance, tolerance and immunity. In the section on epidemiology, which may well have appeared earlier in the manual, the qualities, reproduction and dissemination of micro-organisms are treated, brief consideration being given to methods of host-penetration and survival of the pathogen; further discussion of the parasite in respect of variation and physiological specialization is resumed in later sections.

Eight chapters of the manual are devoted to the subject of disease control, embracing such topics as the economy of disease control, chemical treatment, seed and soil treatment, crop rotation, sanitation, breeding, 'market' pathology (harvest losses, lowtemperature storage, care in handling) and the incidence of 'new' diseases. This excellent manual, apparently the first of a series on plant sciences, closes with a plea for greater public support of agricultural research and for the encouragement of intelligent co-operation between grower and pathologist as contributory in no small measure to the success of the world-wide campaign against food shortage and disease. S. G. JonEs 